tection of subjects who had milder illness but believed they had experienced a cold. The effect of the case definition used by Predy and colleagues is to limit the evaluation to only the most severe illnesses that occur during the influenza season.

Experience has demonstrated the difficulty and importance of sound methodology in preventing bias in studies of common cold prevention. Although numerous therapies, both alternative and conventional, have been reported in preliminary studies to have beneficial effects for the common cold, only a relative handful have proven effective after rigorous and reproducible studies. Further studies that evaluate the effect of wellcharacterized and standardized preparations of ginseng in virologically proven influenza infections or more typical common cold illnesses will be needed to confirm and extend the results of the study reported in this issue.

Ronald Turner is from the Department of Pediatrics, University of Virginia School of Medicine, Charlottesville, Virginia.

Competing interests: Ronald Turner is a consultant to Wyeth Consumer Healthcare, Schering-Plough Research Institute, Nordic Phytopharma A/S, the Dial Corporation and Procter \& Gamble. He has received research funding from Biopolymer Engineering, the Dial Corporation, Antiviral Technologies, Procter \& Gamble and ViroPharma.

\section{REFERENCES}

I. Marshall I. Zinc for the common cold. Cochrane Database Syst Rev 2000: CDoor364.

2. Melchart D, Linde K, Fischer $\mathrm{P}$, et al. Echinacea for preventing and treating the common cold. Cochrane Database Syst Rev 2000;2:CDoo0530.

3. Predy GN, Goel V, Lovlin R, et al. Efficacy of an extract of North American ginseng containing polyfuranosyl-pyranosyl-saccharides for preventing upper respiratory tract infections: a randomized controlled trial. CMAJ 2005;173(9):1043-8.

4. Gern JE, Vrtis R, Grindle KA, et al. Relationship of upper and lower airway cytokines to outcome of experimental rhinovirus infection. Am J Respir Crit Care Med 2000;162:2226-3I.

5. Fritz RS, Hayden FG, Calfee DP, et al. Nasal cytokine and chemokine responses in experimental influenza A virus infection: results of a placebo-controlled trial of intravenous zanamivir treatment. J Infect Dis I999;180:586-93.

6. Hayden FG, Albrecht JK, Kaiser DL, et al. Prevention of natural colds by contact prophylaxis with intranasal alpha2-interferon. N Engl J Med I986;314:7I-5.

7. Hayden FG, Atmar RL, Schilling M, et al. Use of the selective oral neuraminidase inhibitor oseltamivir to prevent influenza. N Engl J Med I999;34I:I336-43.

8. Monto AS, Robinson DP, Herlocher ML, et al. Zanamivir in the prevention of influenza among healthy adults: a randomized controlled trial. JAMA I999;282:31-5.

9. Monto AS, Shope TC, Schwartz SA, et al. Intranasal interferon-a2b for seasonal prophylaxis of respiratory infection. J Infect Dis 1986;154:128-33.

Io. Jackson GG, Dowling HF, Spiesman IG, et al. Transmission of the common cold to volunteers under controlled conditions. I. The common cold as a clinical entity. Arch Intern Med 1958;101:267-78.

Correspondence to: Dr. Ronald B. Turner, University of Virginia School of Medicine, P.O. Box 800386 , Charlottesville, VA 22908; fax 434 982-4246; rbt2n@virginia.edu

\title{
The Declaration of Helsinki: an update on paragraph 30
}

\section{Jeff Blackmer, Henry Haddad}

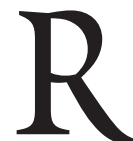

esearch on human subjects is governed by a large number and wide variety of codes and policies worldwide. In Canada, the Tri-Council Policy Statemen $\mathrm{t}^{1}$ must be adhered to by individuals and institutions who receive public funding for research. However, Health Canada and many private funding sources generally use the World Health Organization's guidelines, ${ }^{2}$ which differ slightly from the Tri-Council statement. Internationally, there is little argument that the pre-eminent document addressing research ethics is the Declaration of Helsinki, ${ }^{3}$ adopted by the World Medical Association (WMA) in 1964. This document evolved from the Nuremberg Code, which was put in place to protect human research subjects in response to atrocities committed by Nazi physicians in the name of medical science. The Declaration of Helsinki has $\therefore$ been amended 5 times, most recently in 2000 . The addition of paragraphs 29 and 30 in the amendment of 2000 has been among the more significant and controversial changes made to the document, and subsequently prompted the addition of 2 notes of clarification. The first of these, added in 2002, pertains to paragraph 29, which deals with the use of placebos. Many feel that this note has not served to clarify conditions in which placebos can ethically be used but, rather, may have weakened the intent of the existing paragraph. ${ }^{4}$ Our concern here, however, is with paragraph 30 , which addresses the issue of post-study access to treatment. This paragraph reads as follows:

At the conclusion of the study, every patient entered into the study should be assured of access to the best proven prophylactic, diagnostic and therapeutic methods identified by the study.

This addition to the Declaration has given rise to significant debate and discussion, including in the pages of the journal. ${ }^{5}$ The primary intention of the paragraph is to prevent trial sponsors from performing studies in populations that would not normally have access to the study treatment, only to remove access to the intervention once the trial has been completed. This occurred after some of the trials of HIV/AIDS drug therapy conducted in some African nations in the I99os. Some argued that the research could be justified by the devastation caused by the epidemic, and the fact that these patients could not otherwise obtain medication; others have argued that ethical standards are universal and that all research subjects deserve a certain standard of protection regardless of 
their geographic location. ${ }^{6}$

Opponents of the paragraph argue that it is the responsibility of local health care systems, not the study sponsors, to provide access to ongoing health care and that, in any case, the infrastructure does not always exist to enable study sponsors to ensure this access. They also feel that the financial burden on research sponsors as a result of providing ongoing treatment would be overwhelming and would prevent many companies from conducting studies in developing countries, thus impeding the collection of data on effective treatment delivery in vulnerable populations and adding a further obstacle to the devel-

\section{We must examine not just} the responsibilities of study sponsors but of physician collaborators as well.

opment of drugs for the neglected diseases of the world's poor. Ethically, there is the issue of the responsibilities of physicians to study participants, particularly those who have benefited from the trial medication or intervention and may suffer once it is removed. As the great majority of these trials are run by physician investigators, we must examine not just the responsibilities of study sponsors but of physician collaborators as well. The needs of trial participants may be quite different in a North American or Western context than in the developing world. In Western countries, most patients will have access to needed treatment on the completion of a trial through their local health care system. This is not the case in many developing nations.

Many physicians are increasingly feeling a sense of global responsibility and are recognizing that international policies and documents should not be tailored solely to the Western context. If a policy is intended to provide guidance on a global scale, it must uphold the very highest international ethical standards and should not be compromised to satisfy the needs of only a few, especially when those needs are at least partly motivated by financial interest.

There has been a lot of discussion about how best to address the concerns surrounding paragraph 30 . Two separate working groups have considered the issue and have made various recommendations, including revising the paragraph, adding a preamble and providing a note of clarification (such as was added to paragraph 29). At a meeting of the WMA Council in France in May 2004 the American Medical Association proposed the following note of clarification:

The WMA hereby reaffirms its position that it is necessary during the study planning process to identify post-trial access by study participants to prophylactic, diagnostic and therapeutic procedures identified as beneficial in the study or access to other appropriate care. Post-trial access arrangements or other care must be described in the study protocol so the ethical review committee may consider such arrangements during its review.

Despite the opposition of several national medical associations, including the CMA, this note was approved by WMA Council. It was subsequently brought forward to the WMA General Assembly in Tokyo in October 2004. Surprisingly, there was no discussion or debate on the issue in Tokyo. The note of clarification received $7 \mathrm{I}$ of a possible 87 votes and was passed, with Canada and a few other countries abstaining. If sponsors are required only to identify whether or not they will be providing post-trial access to ongoing treatment, there is no real onus on them to do so. According to the note of clarification, they fulfill their ethical obligation simply by discussing the issue. In the case of pharmaceutical trials in developing countries, one can easily imagine sponsors identifying the fact that they would like to provide ongoing access to the study medication at the conclusion of the trial but are unable to do so for financial reasons. They could then describe the fact that no post-trial care would occur. If the relevant ethical review committee concurred, the trial would proceed. In many of these trials, the ethical review might take place not in the country where the trial is to be done, but in the home country of the sponsor, often by a private, for-profit research ethics board.

The CMA will continue to advocate on behalf of patients and physicians in developing nations who find themselves without access to proper medical care, and encourages all Canadian physicians to do the same. In today's global environment, physicians need to be concerned not only with local issues of access, but with international ones as well. We will be following developments in this area closely and will bring forward any concerns to the WMA as they arise, particularly if there is any evidence that the note of clarification is being used as many fear it might be.

Jeff Blackmer is Executive Director of the CMA's Office of Ethics, and Henry Haddad is a Past President of the CMA.

\section{REFERENCES}

I. Tri-Council policy statement: ethical conduct for research involving humans Ottawa: Medical Research Council of Canada, Natural Sciences and Engineering Research Council and Social Sciences and Humanities Research Council of Canada. Available: www.ncehr-cnerh.org/english/code_2 (accessed 2004 Sept 2I).

2. World Health Organization. Guidelines for good clinical practice (GCP) for trials on pharmaceutical products. WHO Technical Report Series no. 850, 1995, Annex 3.

3. World Medical Association. Declaration of Helsinki: ethical principals for research involving human subjects. As amended in Tokyo, 2004. Ferney-Voltaire, France: The Association; 2004. Available: www.wma.net/e/ethicsunit/helsinki.htm (accessed 2005 Sept 26).

4. Sacca L. Placebo in clinical research: a continual compromise between ethical requirements and scientific rigor. Ann Ital Med Int 2002;17(4):215-20.

5. Dismantling the Helsinki declaration [editorial]. CMAJ 2003;169(I0):997.

6. Angell M. Investigators' responsibilities for human subjects in developing countries. NEngl J Med 2000;342(13)967-9.

Correspondence to: Dr. Jeff Blackmer, Office of Ethics, Canadian Medical Association, I867 Alta Vista Dr., Ottawa ON KIG 3 Y6; fax6I373I-I779; jeff.blackmer@cma.ca 